\title{
Hear No Evil, See No Evil? Associations of Gender, Trauma History, and Values with Believing Trauma Vignettes
}

\author{
Lisa DeMarni Cromer* \\ University of Tulsa
}

\section{Jennifer J. Freyd \\ University of Oregon}

Attitudes and beliefs about sexual assault in general influence judgments about the veracity of specific sexual assault reports and disclosures (Taylor, 2007). The present study investigated the impact of gender, personal trauma history, and beliefs about gender and child sexual abuse (CSA) on judgments of the veracity of CSA disclosures. The study also examined judgments about other kinds of trauma disclosures using a variety of different types of trauma vignettes. Men were found to be more skeptical than women, and those who reported no trauma history were less likely than those who reported a trauma history to believe disclosures. Overall, all participants were more skeptical about CSA disclosures than disclosures about other kinds of trauma. Sexism and belief in CSA myths (CSAMs) were negatively related to believing adults' retrospective CSA disclosures. In a series of regression analyses, we observed that belief in CSAMs moderated the negative association between sexist attitudes and believing disclosures. Implications for educating professionals are discussed.

Child sexual abuse (CSA) is a major public health issue (WHO, 2002). Approximately one-third of females and one-sixth of males will be sexually abused before they reach adulthood (Kendall-Tackett, Williams, \& Finkelhor, 1993). Despite these high base rates, reports about CSA are sometimes viewed with excessive skepticism. Doubts about CSA disclosures are expressed in myriad ways

\footnotetext{
* Correspondence concerning this article should be addressed to Lisa DeMarni Cromer, Department of Psychology, 800 S. Tucker Drive, Tulsa, Oklahoma 74104 [e-mail: lisa-cromer@utulsa.edu].

This research was supported by a grant awarded to the first author by the Center for the Study of Women in Society at the University of Oregon.
}

85 
(Cromer \& Goldsmith, in press). This includes queries regarding how broadly CSA is defined (Cromer \& Goldsmith, in press) as well as whether an abuse actually occurred when an adult had sex with a child (Cromer \& Freyd, 2007). The veracity of CSA reports made by women and children is also challenged when they are believed to be manufactured out of malice or for personal gain (Brown, Frederico, Hewitt, \& Sheehan, 2001). Skepticism impacts juries and judicial decisions in criminal and civil cases (Hamilton, 2008) as well as professionals who provide victim services (Collings, 2003). The present study focuses on reactions to adults' delayed disclosures of CSA, which has implications for many civil court proceedings, such as accusations of clergy abuse made decades after the alleged abuse occurred. Previous work has found that adult retrospective reporting of traumas that were not continuously remembered was believed less than traumas that were continuously remembered (Cromer \& Freyd, 2007). The current work focuses on instances in which traumas were continuously remembered (vignettes state that the victim has always remembered the disclosed trauma). By assuring continuity in described memory, we are able to examine other variables that affect the perceived believability of disclosures.

Data show that gender is the most robust individual difference variable that impacts believing CSA reports. The psychological literature is replete with evidence that male jurors (e.g., McCauley \& Parker, 2001; Quas, Bottoms, Haegerich, \& Nysse-Carris, 2003) and male college students do not believe CSA disclosures as much as females do (Cromer \& Freyd, 2007; Cromer \& Goldsmith, in review). Contributing third variables that have been ruled out include gender role attitudes (Maynard \& Widerman, 1997), sex-role stereotyping, acceptance of interpersonal violence (O'Donohue, Elliot, Nickerson, \& Valentine, 1992), and being a parent (Jackson \& Nuttall, 1994). However, sexism relates to judgments about adult victim culpability in rape cases (Abrams, Viki, Masser, \& Bohner, 2003) and to approval of sexual coercion with adults (Forbes, Adams-Curtis, \& White, 2004). Sexism is related to believing CSA disclosures as well as to ratings of how abusive it is for an adult to have sex with a child (Cromer \& Freyd, 2007). Personal trauma history also matters. In a large clinician sample, personal history of CSA increased believing CSA allegations (Nuttall \& Jackson, 1994). In a college sample, Cromer and Freyd (2007) found that males with no history of childhood interpersonal trauma were more skeptical of abuse reports compared to males with a history of childhood interpersonal trauma, while trauma history was not significantly related to females' believing. What is unclear from this research is whether males with no history of any childhood trauma are generally more skeptical or whether this bias is specific to CSA.

\section{Believing \& Disclosure: Implications}

In the last decade, there has been increased awareness of the problem of CSA. Nonetheless, up to $86 \%$ of victims do not report to authorities (Kilpatrick, 
Saunders, \& Smith, 2003) and in retrospective studies, the modal rate of childhood disclosure to anyone is $33 \%$ (London, Bruck, Ceci, \& Shuman, 2005). Disclosure rate is higher for stranger rape (Smith et al., 2000), which has a lower base rate than CSA. When victims disclose, there typically is a delay ranging from one month to decades (Somer \& Szwarcberg, 2001), and disclosure is less common if CSA is perpetrated by a caregiver (Goodman-Brown, Edelstein, Goodman, Jones, \& Gordon, 2003).

Disclosure affects health outcomes of CSA. Disclosing to a supportive person can have physical and mental health benefits (Hyman, Gold, \& Cott, 2003) and social support can mitigate long-term sequelae of CSA (Hyman et al., 2003; Ullman $\&$ Filipas, 2005). Further, disclosure can reduce the incidence of Posttraumatic Stress Disorder (Hyman et al., 2003), in contrast to tangible, material aid, which does not (Ullman \& Filipas, 2005).

Nonetheless, disclosure can backfire. An adverse response to CSA disclosure, such as disbelief and blame, can exacerbate the negative health and psychological outcomes (Ullman \& Filipas, 2005). Given that male support providers are less helpful when disclosed to (Armsworth, 1989), gender and beliefs about gender (sexism) are important considerations in disclosure research.

\section{Preconceptions about Rape and Child Sexual Abuse}

Nearly three decades ago, Martha Burt postulated that the belief systems of lay people and professionals reflected rape myth acceptance (1980). Rape myths, "defined as prejudicial, stereotyped, or false beliefs about rape, rape victims, and rapists" (p. 217), like other stereotypes, are perpetuated by isolated cases. For example, in Burt's 1980 research, 50\% of participants believed that in anger and retaliation, woman often lie about rape. In contrast, FBI statistics at the time evidenced only $2 \%$ of rapes being falsely reported, a rate that paralleled false reports of other felonies (Lonsway \& Fitzgerald, 1994). Rape myths function to rationalize the high incidence of rape and shift responsibility from the perpetrator (Lonsway \& Fitzgerald, 1994). Rape myths relate to acceptance of interpersonal violence and to believing that sexual relationships are "fundamentally exploitative" (Burt, 1980, p. 218).

CSAMs are analogous to rape myths. CSAMs deny the harm and prevalence of CSA and challenge the veracity of disclosures (Cromer \& Goldsmith, in press). CSAMs include beliefs that adult sex with children is not abusive or harmful. They include stereotypes that women and children often lie about CSA for retaliation or gain (Collings, 1997). These myths exist in the psychological literature, the media, and in courtrooms (Cromer \& Goldsmith; Hamilton, 2008). These beliefs are held by psychologists and lay people (Collings, 2003) as well as by judges (Hamilton, 2008). Like rape myths, CSAMs are supported by sensationalized cases that garner media attention. They are subtly reinforced by the media's lexical choices. Words like "affair" or "fondling" appear to further obfuscate the harm of CSA (Collings 
\& Bodill, 2003, p. 170). Additionally, perpetrators and defense attorneys may spin CSA, arguing that there is no harm if children experience pleasure or physical affection (Hamilton, 2008).

\section{Evidence against CSA Myths}

CSAMs persist despite overwhelming contrary evidence (Cromer \& Goldsmith, in press). A substantive literature evidences that CSA is harmful (Freyd et al., 2005). Meta-analyses confirm that CSA is a precursor to numerous mental health and interpersonal difficulties (Paolucci, Genuis, \& Violato, 2001). Contrary to myths that CSA is uncommon or that rates are exaggerated, expansive research of industrialized nations finds prevalence rates of $20 \%$ for females and up to $10 \%$ for males (WHO, 2002). Further, the harmful mental and physical health effects of CSA are consistently found across studies regardless of the definition of CSA (Paolucci et al., 2001). Finally, beliefs that CSA reports are frequently false are contrary to data. False claims of CSA are the exception, with studies finding as few as $2 \%$ to $4 \%$ of cases being false (Oates et al., 2000; Trocmé, Tourigny, MacLaurin, \& Fallin, 2003). Contrary to public perception, only about $2 \%$ of child custody cases in court involve CSA allegations (Schudson, 1992).

Although CSAMs parallel rape myths, the CSAM literature is limited in scope. CSA impacts nearly a quarter of the population (Freyd et al., 2005), yet there is a paucity of research about preconceptions of CSA disclosures, particularly in relation to preconceptions and attitudes about CSA. The present study examines beliefs in CSAMs in relation to gender and trauma history in order to examine individual differences in perceptions about the veracity of disclosures.

\section{Objectives}

This project measured level of belief in retrospective disclosures of childhood trauma. Previous work had found that gender and trauma history were associated with believing CSA disclosures (Cromer \& Freyd, 2007). We examined whether this bias was unique to disclosures of CSA or if it would generalize to other interpersonal trauma (e.g., domestic violence) and to other kinds of trauma (e.g., motor vehicle accident).

We also investigated the influence of beliefs about gender (sexism) and beliefs about CSA on believing disclosures. We hypothesized that sexism and beliefs in CSAMs would predict disbelief in interpersonal trauma but not about other trauma disclosures. Extending earlier research that found that sexist attitudes were related to believing that adult females were more culpable and acted inappropriately so as to invite rape (Abrams et al., 2003), it was expected that both sexism and belief in CSAMs would be negatively associated with believing CSA disclosures. 


\section{Methods}

\section{Participants}

Two hundred fifty nine (89 males, 169 females, 1 unidentified) students in introductory psychology and linguistics classes participated for course credit. Mean age was 21.62 years $(S D=6.15)$, Median $=20$ years. Sixty eight percent of participants were Caucasian, 8.9\% Asian/Pacific-Islander, 3.1\% African American, 2.3\% Hispanic, and 6.9\% "other," which included biracial participants. Participants did not self-select into the study based on knowledge of the content; rather, participants were selected for the study based on schedule availability from a large human subject pool.

\section{Materials}

Participants completed measures of sexism, belief in CSAMs, and trauma history. The old-fashioned and modern sexism scales (Swim, Aikin, Hall, \& Hunter, 1995) queried beliefs in traditional and contemporary sexism. An example of old-fashioned sexism is, "Women are generally not as smart as men," and an example of modern sexism is, "The government and news media have been showing more concern about the treatment of women than is warranted by women's actual experiences." Responses range from $1=$ strongly disagree to $5=$ strongly agree. The Child Sexual Abuse Myth Scale (CSAMS; Collings, 1997) assessed three aspects of CSAMs: blame diffusion, denial of abusiveness, and restrictive stereotypes. Responses range from $1=$ completely disagree to $5=$ completely agree with myths. Convergent and discriminant validity with rape myths and incest blame scales are established (Collings, 1997). The Brief Betrayal Trauma Survey (BBTS; Goldberg \& Freyd, 2006) is an inventory of interpersonal and noninterpersonal trauma. An example of interpersonal trauma is, "Made to have some form of sexual contact. . by someone with whom you were very close." An example of a noninterpersonal trauma is, "A major earthquake, fire, flood, hurricane, or tornado."

Participants were presented with 10 vignettes that described trauma disclosures by a hypothetical college friend or classmate. The vignettes were varied for types of trauma and we controlled for vignette length, number of details, and age at time of victimization. Four vignettes contained noninterpersonal trauma disclosures such as having one's arm smashed in several places in a high speed motor vehicle accident at age nine, and six vignettes contained interpersonal trauma such as witnessing domestic violence ("he saw his father break his mother's arm") or the victim disclosing having been sexually molested at age nine by a stepfather. Participants rated believability $(0=$ not at all to $5=$ very believable $)$ for each disclosure. 


\section{Procedures}

Surveys were completed online using Sona Systems ${ }^{\mathrm{TM}}$ human subjects pool software. This survey system provided a unique randomized order of instruments for each participant. Additionally, the vignettes were administered in a unique randomized presentation to each participant. Version 16 of the Statistical Package for the Social Sciences (SPSS) software was used for data analyses.

\section{Results}

\section{Gender and Trauma History}

Sixty-eight percent of males and females reported at least one childhood trauma (e.g., car accident); $27 \%$ of males and $33 \%$ of females experienced at least one type of interpersonal childhood trauma (e.g., sexual abuse). History of interpersonal childhood trauma was a dichotomous variable (i.e., yes or no). Vignette score ratings were continuous variables: interpersonal vignette believing $M=3.70(S D=.87)$, range .75 to 5.0 , skewness $=-.358$; noninterpersonal vignette believing $M=4.21(\mathrm{SD}=.88)$, range .75 to 5.0 , skewness $=-.22$.

A repeated measures 2 (gender) $\times 2$ (trauma history) $\times 2$ (vignette type) BBW design MANOVA examined differences in amount of belief in hypothetical disclosures of interpersonal trauma and other kinds of trauma. The multivariate test was significant for differences between the two dependent variables (i.e., vignette type), Wilks' Lambda $=.64, F(1,254)=140.26, p<.001$, partial $\eta^{2}=.356$. There was a between subject main effect for gender $F(1,254)=3.95, p<.05$, partial $\eta^{2}=.02$ and a between subject main effect for participants' trauma history $F(1,254)=4.62, p<.05$, partial $\eta^{2}=.02$ (means and standard deviations appear in Figure 1). Interpersonal trauma vignettes were believed less than were vignettes about other kinds of trauma. Females believed disclosures more than did males, and individuals reporting a history of childhood trauma believed disclosures more than did participants who did not report a childhood interpersonal trauma history.

\section{Predicting Vignette Ratings}

This study investigated values, which theoretically could influence judgments about disclosures: beliefs about CSAMs and beliefs about gender (sexism). CSAM and sexism were continuous variables. CSAM $M=4.39(S D=.52)$, range 2.6 to 5.0, and sexism $M=2.04$ ( $S D=.45)$, range 1.31 to 3.69 .

We hypothesized that more sexism and believing CSAMs would negatively relate to belief in interpersonal trauma vignettes. Both of these measures were entered into a regression analysis (Model 1, Table 1), with level of belief in vignettes entered as the continuous dependent variable. Although the overall regression 


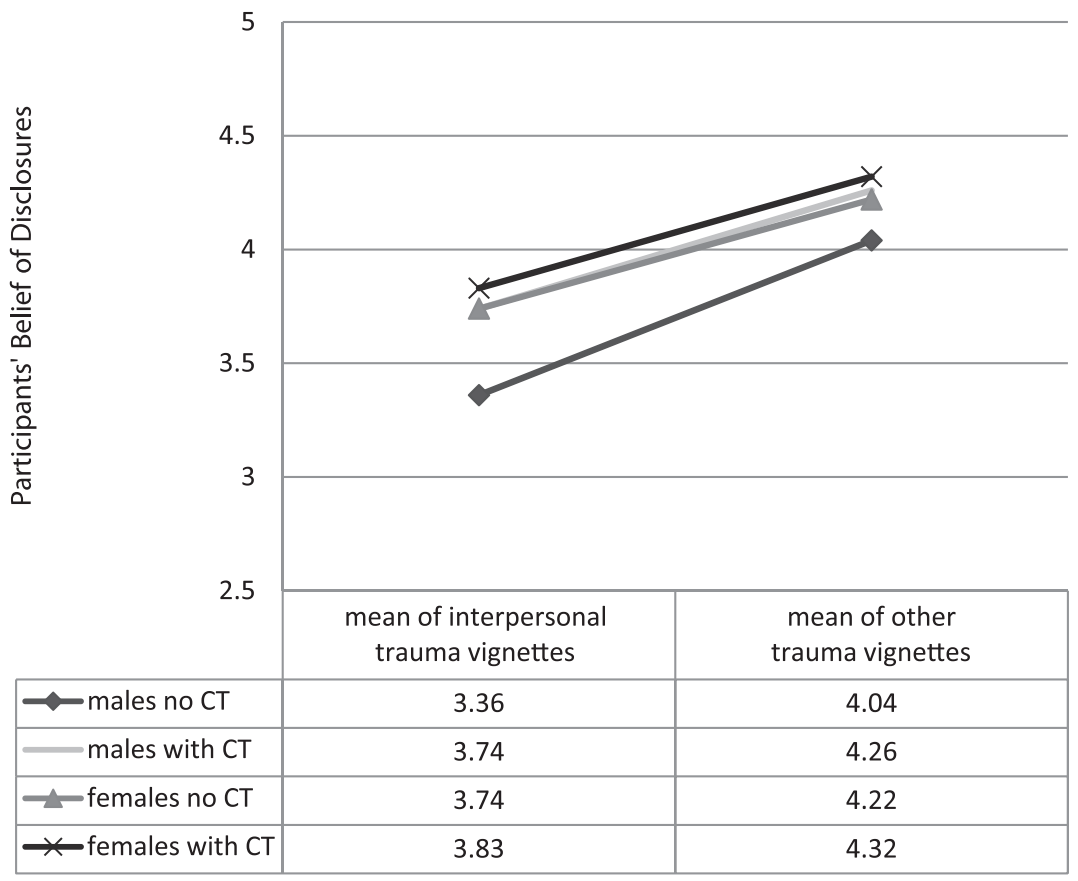

Fig. 1. Mean believability ratings for vignettes about interpersonal trauma and about noninterpersonal trauma shown by participant gender and trauma history. CT $=$ self-reported history of childhood interpersonal trauma.

Table 1. Regression Models

\begin{tabular}{lllllll}
\hline IV & DV & $\mathrm{r}^{2}$ & $\mathrm{~B}$ & Beta & $\mathrm{t}$ & sig. \\
\hline Model 1: Sexism & Vignette & .103 & -.227 & -.118 & 1.713 & .09 \\
CSAM & & & .428 & .257 & 3.739 & .000 \\
Model 2: CSAM & Vignette & .09 & .50 & .302 & 4.75 & .000 \\
Model 3: Sexism & CSAM & .15 & -.447 & -.386 & 6.712 & .000 \\
Model 4: Sexism & Vignette & .05 & -.419 & -.217 & 3.327 & .001 \\
\hline
\end{tabular}

CSAMS $=$ Child Sexual Abuse Myth Scale.

explained a significant amount of variation, $F(6,247)=4.63, p<.001$, it was only the CSAM measure that contributed significantly to the explanatory power of the model. This model was rerun with the CSAM as the only predictor of belief in the vignettes (shown as Model 2 in Table 1). Because it was unexpected that sexism would not significantly contribute to the model, additional exploratory analyses were conducted in order to understand the nature of the relationship between variables. We regressed level of belief in vignettes onto sexism and then regressed CSAM onto sexism. These models both explained a significant amount 


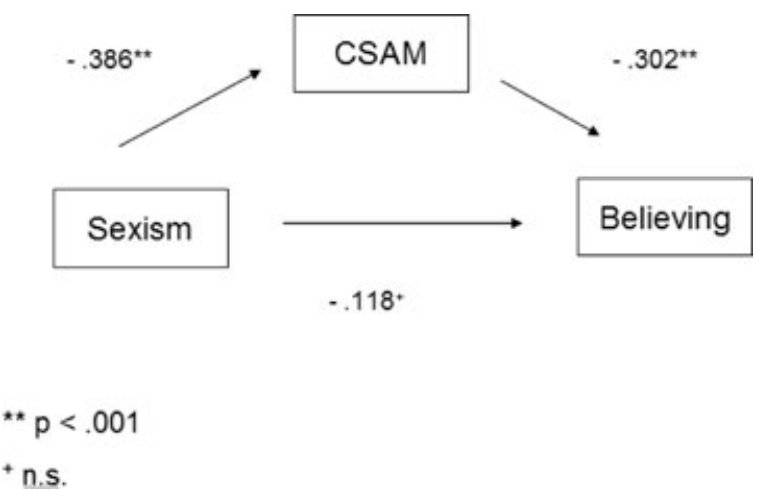

Fig. 2. Mediational model demonstrating the relationship between beliefs in gender, beliefs in CSAM and believing vignettes.

of variation (Models 3 and 4 in Table 1). From these analyses, we see that a higher level of sexism was associated with lower belief in interpersonal trauma disclosures, but also that more belief in CSAMs was associated with lower belief in disclosures, over and above relations of sexism (Figure 2).

\section{Discussion}

This study examined gender, trauma history, and values about both sexism and CSA as factors that may influence believing adult retrospective disclosures about interpersonal childhood trauma. We extended earlier work (Cromer \& Freyd, 2007) by demonstrating that gender and reported trauma history impact judgments of not only CSA but also of other interpersonal childhood trauma. We also found that these criteria did not impact judgments of noninterpersonal trauma. In our sample, $27 \%$ of males and $33 \%$ of females reported at least one childhood interpersonal trauma. Given that this self-reported experience relates to different perceptions of others' reports, personal history of trauma will be an important factor to consider for future research that evaluates believing or not believing disclosures. It may be that judges and juries who have not had personal experience with childhood trauma are more skeptical about the veracity of child abuse reports in criminal and custody cases. It may also be the case that juries composed of CSA victims may be more likely to find an accused perpetrator guilty. These results suggest that using expert witnesses (or other means of education about the prevalence, typical presentation of, and typical disclosure characteristics of CSA victims) may be necessary to reduce bias within the legal system (Freyd, 2008). For example, judges in civil and family court may benefit from education about CSAMs and facts.

This study also found that sexism related to agreement with CSAMs, irrespective of participants' gender. Historically it has been feminists who advocated 
for children and worked against CSA (Olafson, 2002). Thus, these findings are consistent with historical trends in that feminists are more likely to recognize CSA prevalence and more likely to see CSA as harmful (Scheper-Hughes, 1998). Thus, while gender has been a focus of past research on believing disclosures, assumptions and biases will be important considerations for future work.

Finally, one objective of this study was to examine the relationship between beliefs about gender and CSAMs and believing retrospective disclosures of interpersonal trauma. Regression analyses indicated that believing CSAMs negatively related to the amount of belief of CSA disclosures. Given that previous research has found that sexism was associated with believing that adult female rape victims were culpable for their victimization (Abrams et al., 2003), we conducted a series of regressions to further examine beliefs in disclosures. Analyses revealed that sexism was positively related to belief in CSAMs and also that sexism was associated with more belief of CSA disclosures in the vignettes. However, when belief in myths was controlled, sexism no longer predicted believing disclosures. In other words, beliefs in CSAMs mediated the sexism-believing relationship. This provides evidence that we need to look beyond demographic variables (gender), personality variables (sexism), and consider (mis)information and biases that impact decision making. Judgments about the veracity of CSA reports weigh plausibility ("Could it have happened?") and probability ("Was it likely to have happened?"). These analyses indicate that personal experience impacts judgments about the believability of abuse disclosures. This suggests that personal trauma history could be an important variable to consider in jury composition. From a public policy perspective, it could contribute to predicting individual differences in who will support policies that relate to child protection as well as to statutes of limitations regarding civil and criminal proceedings when adults come forward about alleged CSA.

\section{Limitations and Future Directions}

Participants in this study were college students enrolled in introductory psychology and linguistics classes. Although students are of age for jury duty and therefore may represent typical characteristics of juries (Quas et al., 2002), it is also possible that the restricted age and student status of this sample limits the generalizability of these findings to more diverse populations. In the future, we anticipate continuing this line of work with professionals whose judgments about disclosures may relate to some aspect of their profession, such as teachers, police officers, judges, and clergy. This study utilized self-report for trauma history and attitudes about gender and CSAMs. An inherent difficulty in this methodology is the likelihood of under-reporting (Fergusson, Horwood, \& Woodward, 2000), particularly given the stigma associated with being perceived as a victim or being sexist. Additionally, given the rape myth research that has found that individuals 
who uphold rape myths do not acknowledge their own rape experiences (Peterson \& Meuhlenhard, 2004), it is possible that some individuals who hold CSAMs do not acknowledge their own CSA. Longitudinal research could address this limitation. Future research could extend the present work by examining the influence of context on believing CSA disclosures. In particular, it would be of interest to examine reports made to a physician versus a police officer. Stereotyped beliefs about CSA and personal history of trauma may be important considerations when training health care professionals and police officers or when selecting members of a jury. Finally, the stimuli for this study employed vignettes with retrospective reporting of CSA. This is a strength from a policy perspective, given that many disclosures of CSA occur long after the abuse happened (London et al., 2005). Nonetheless, in future research we will examine the believability of children disclosing sexual abuse. Children disclosing current or recent past abuse have different ramifications than adults disclosing past abuse, and therefore presents an important line of inquiry.

\section{References}

Abrams, D., Viki, G. T., Masser, B., \& Bohner, G. (2003). Perceptions of stranger and acquaintance rape: The role of benevolent and hostile sexism in victim blame and rape proclivity. Journal of Personality and Social Psychology, 84, 111-125.

Armsworth, M. W. (1989). Therapy of incest survivors: Abuse or support. Child Abuse and Neglect, $13,549-562$.

Brown, T., Frederico, M., Hewitt, L., \& Sheehan, R. (2001). The child abuse and divorce myth. Child Abuse Review, 10, 113-124.

Burt, M. R. (1980). Cultural myths and supports for rape. Journal of Personality and Social Psychology, $38,217-230$.

Collings, S. J. (1997). Development, reliability, and validity of the child sexual abuse myth scale. Journal of Interpersonal Violence, 12, 665-674.

Collings, S. J. (2003). Child sexual abuse myth acceptance among aspirant, trainee, and registered psychologists in Durban, South Africa. Social Behavior and Personality, 31, 835-842.

Collings, S. J., \& Bodill, B. (2003). Methodological issues in research on child sexual abuse attributions. South African Journal of Psychology, 33, 170-175.

Cromer, L. D., \& Goldsmith, R. E. (in press). Child sexual abuse myths: Attitudes, beliefs, and individual differences. Journal of Child Sexual Abuse.

Cromer, L. D., \& Freyd, J. J. (2007). What influences believing abuse reports? The role of depicted memory persistence, participant gender and trauma history. Psychology of Women Quarterly, $31,13-22$.

Fergusson, D. M., Horwood, L. J., \& Woodward, L. J. (2000). The stability of child abuse reports: A longitudinal study of the reporting behavior of young adults. Psychological Medicine, 30, 529-544.

Forbes, G. B., Adams-Curtis, L. E., \& White, K. B. (2004). First- and second-generation measures of sexism, rape myths and related beliefs, and hostility toward women: Their interrelationships and association with college students' experiences with dating aggression and sexual coercion. Violence Against Women, 10, 236-261.

Freyd, J. J. (2008) What juries don't know: Dissemination of research on victim response is essential for justice. Trauma Psychology, Division 56, American Psychological Association, Newsletter, $3,15-18$.

Freyd, J. J., Putnam, F. W., Lyon, T. D., Becker-Blease, K. A., Cheit, R. E., Siegel, N. B., \& Pezdek, K. (2005). The science of child sexual abuse. Science, 308, 501. 
Goldberg, L. R., \& Freyd, J. J. (2006). Self-reports of potentially disturbing experiences in an adult community sample: Gender differences in event frequencies, test-retest stabilities, and the hierarchical factor structure of the items in a brief betrayal-trauma survey. Journal of Trauma and Dissociation, 7, 39-63.

Goodman-Brown, T. B., Edelstein, R. S., Goodman, G. S., Jones, D. P. H., \& Gordon, D. S. (2003). Why children tell: A model of children's disclosure of sexual abuse. Child Abuse and Neglect, $27,525-540$.

Hamilton, M. A. (2008). Justice denied: What American must do to protect its children. New York, NY: Cambridge University Press.

Hyman, S. M., Gold, S. N., \& Cott, M. A. (2003). Forms of social support that moderate PTSD in childhood sexual abuse survivors. Journal of Family Violence, 18, 295-300.

Jackson, H., \& Nuttall, R. (1994). Effects of gender, age, and history of abuse on social workers' judgments of sexual abuse allegations. Social Work Research, 18, 105-113.

Kendall-Tackett, K. A., Williams, L. M., \& Finkelhor, D. (1993). Impact of sexual abuse on children: A review and synthesis of recent empirical studies. Psychological Bulletin, 113, 164-180.

Kilpatrick, D. G., Saunders, B. E., \& Smith, D. W. (2003). Youth victimization: Prevalence and implications. Research in brief. NCJ 194972, Washington, DC: National Institute of Justice, April. Retrieved February 10, 2005 from: http://www.ncjrs.gov/pdffiles1/nij/194972.pdf.

London, K., Bruck, M., Ceci, S. J., \& Shuman, D. W. (2005). Disclosure of child sexual abuse: What does the research tell us about the ways that children tell? Psychology, Public Policy, and Law, $11,194-226$.

Lonsway, K. A., \& Fitzgerald, L. F. (1994). Rape myths: In review. Psychology of Women Quarterly, 18, 133-164.

McCauley, M. R., \& Parker, J. F. (2001). When will a child be believed? The impact of the victim's age and juror's gender on children's credibility and verdict in a sexual abuse case. Child Abuse and Neglect, 25, 523-539.

Maynard, C., \& Widerman, M. (1997). Undergraduate students' perceptions of child sexual abuse: Effects of age, sex and gender-role attitudes. Child Abuse and Neglect, 21, 833-844.

Nuttall, R., \& Jackson, H. (1994). Personal history of childhood abuse among clinicians. Child Abuse and Neglect, 18, 455-472.

Oates, R. K., Jones, D. P., Denson, D., Sirotnak, A., Gary, N., \& Krugman, R. D. (2000). Erroneous concerns about child sexual abuse. Child Abuse and Neglect, 24, 149-157.

O'Donohue, W. T., Elliott, A. N., Nickerson, M., \& Valentine, S. (1992). Perceived credibility of children's sexual abuse allegations: Effects of gender and sexual attitudes. Violence and Victims, $7,147-155$.

Olafson, E. (2002). When paradigms collide: Roland Summit and the rediscovery of child sexual abuse. In J. Cone (Ed.), Critical issues in child sexual abuse (pp. 71-106). Thousand Oaks, CA: Sage.

Paolucci, E. O., Genuis, M. L., \& Violato, C. (2001). A meta-analysis of the published research on the effects of child sexual abuse. The Journal of Psychology, 135, 17-36.

Peterson, Z. D., \& Meuhlenhard, C. L. (2004). Was it rape? The functions of women's rape myth acceptance and definitions of sex in labeling their own experiences. Sex Roles, 51, 129-144.

Quas, J. A., Bottoms, B. L., Haegerich, T. M., \& Nysse-Carris, K. L. (2003). Effects of victim, defendant and juror gender on decisions in child sexual assault cases. Journal of Applied Social Psychology, 32, 1993-2021.

Scheper-Hughes, N. (1998). Institutionalized sex abuse and the Catholic church. In N. Scheper-Hughes \& C. Sargent (Eds.), Small wars: The cultural politics of childhood (pp. 295-317). Los Angeles, CA: University of California Press.

Schudson, C. B. (1992). Antagonistic parents in family courts: False allegations or false assumptions about true allegations of child sexual abuse? Journal of Child Sexual Abuse, 1, 113-116.

Smith, D. W., Letourneau, E. J., Saunders, B. E., Kilpatrick, D. G., Resnick, H. S., \& Best, C. L. (2000). Delay in disclosure of childhood rape: Results from a national survey. Child Abuse and Neglect, 24, 273-287.

Somer, E., \& Szwarcberg, S. (2001). Variables in delayed disclosure of childhood sexual abuse. American Journal of Orthopsychiatry, 71, 332-341. 
Swim, J. K., Aikin, K. J., Hall, W. S., \& Hunter, B. A. (1995). Sexism and racism: Old-fashioned and modern prejudices. Journal of Personality and Social Psychology, 68, 199-214.

Taylor, N. (2007). Juror attitudes and biases in sexual assault cases. Trends \& Issues in Crime and Criminal Justice. Australian Government, Australian Institute of Criminology, No. 344.

Trocmé, N. M., Tourigny, M., MacLaurin, B., \& Fallin, B. (2003). Major findings from the Canadian incidence study of reported child abuse and neglect. Child Abuse and Neglect, 1427-1439.

Ullman, S. E., \& Filipas, H. H. (2005). Gender differences in social reactions to abuse disclosures, post-abuse coping, and PTSD of child sexual abuse survivors. Child Abuse and Neglect, 29, 767-782.

World Health Organization: WHO. (2002). World report on violence and health, WHO, Geneva, 2002 (pp. 82-111). Retrieved April 15, 2006, from: http://www.who.int/violence_injury_ prevention/violence/world_report/.

JENNIFER J. FREYD is Professor of Psychology at the University of Oregon. Freyd directs a laboratory investigating the causes and impact of trauma, particularly child abuse, on physical health, mental health, behavior, and society. The author or coauthor of numerous articles, Freyd also wrote Betrayal Trauma: The Logic of Forgetting Childhood Abuse. She currently serves as the editor of the Journal of Trauma \& Dissociation and is chair of the Science Committee of APA's Trauma Psychology Division (Div 56). Freyd is a Fellow of the American Association for the Advancement of Science.

LISA DEMARNI CROMER is Assistant Professor of Psychology at the University of Tulsa, where she is also the director of SPARTA Lab (Studies of Prevention of, and Adjustment and Resilience to, Trauma and Adversity). She serves on the editorial board of the Journal of Trauma \& Dissociation and has recently joined the editorial board for Psychological Trauma, which is the journal of APA's Trauma Psychology Division (Div 56). Cromer serves as the Chair of the Early Career Psychologist Committee of Div 56, and is on the Advisory Board for the Leadership Council on Child Abuse and Interpersonal Violence. 